\title{
Causes of isolated recurrent ipsilateral sixth nerve palsies in older adults: a case series and review of the literature
}

This article was published in the following Dove Press journal:

Clinical Ophthalmology

23 February 2015

Number of times this article has been viewed

\author{
Jane W Chan ${ }^{1,2}$ \\ Jeff Albretson ${ }^{3}$ \\ 'Department of Neurology, \\ 2Department of Ophthalmology, \\ College of Medicine, University of \\ Arizona, Phoenix, AZ, USA; ${ }^{3}$ University \\ of Nevada, Las Vegas, NV, USA
}

Purpose: The etiology of recurrent isolated sixth nerve palsies in older adults has not been well described in the literature. Sixth nerve palsies presenting with a chronic, relapsing, and remitting course are uncommon, but can herald a diagnosis of high morbidity and mortality in the older population.

Patients and methods: Our method was a retrospective case series study. A review of clinical records of 782 patients $\geq 50$ years of age diagnosed with recurrent sixth nerve palsies was performed over a 10-year period from 1995-2005 in a neuro-ophthalmology clinic in Reno, Nevada. A review of the current literature regarding similar cases was also performed on PubMed.

Results: Seven patients $\geq 50$ years of age with chronic, recurrent sixth nerve palsies were identified. Five were males and two were females. Four of seven (57\%) patients had structural lesions located in the parasellar or petrous apex cavernous sinus regions. One of seven (14.29\%) had a recurrent painful ophthalmoplegic neuropathy (International Headache Society [IHS] 13.9), previously termed ophthalmoplegic migraine; one of seven (14.29\%) presented with an intracavernous carotid artery aneurysm; and one of seven (14.29\%) presented with microvascular disease.

Conclusion: The clinical presentation of an isolated recurrent diplopia from a sixth nerve palsy should prompt the neurologist or ophthalmologist to order a magnetic resonance imaging (MRI) scan of the brain with and without gadolinium as part of the initial workup to rule out a non-microvascular cause, such as a compressive lesion, which can increase morbidity and mortality in adults $>50$ years of age.

Keywords: cranial nerve palsy, skull base tumor, aneurysm, meningioma, ophthalmoplegic migraine, microvascular disease

\section{Introduction}

Sixth nerve palsies are attributed to the following causes: $8 \%-30 \%$ idiopathic, $10 \%-30 \%$ miscellaneous, $3 \%-30 \%$ trauma, $0 \%-6 \%$ aneurysm, and $0 \%-36 \%$ ischemic. ${ }^{1}$ The sixth cranial nerve is the most commonly affected of the ocular motor nerves because of its long intracranial course after emerging at the pontomedullary sulcus and then into the orbits, where it innervates the lateral rectus muscle. The points of fixation along its course, its tortuosity, and its attachment to the skull base all contribute to its vulnerability to compression. ${ }^{1}$ Although the presence of vasculopathic risk factors in patients at least 50 years of age is a significant predictor for a presumed microvascular cause for an acute isolated ocular motor mononeuropathy, a previous multicenter study showed that $16.5 \%$ of 109 patients had a non-microvascular cause, such as a neoplasm or infarct. Sixth nerve palsies were the most common in this study cohort and they were acute and non-recurrent. ${ }^{2}$ The current study focuses on a subpopulation of isolated relapsing-remitting sixth nerve palsies in which we present evidence that mass lesions
Correspondence: Jane W Chan

Barrow Neurological Institute, 240 W

Thomas Road, Suite 40I, Phoenix,

AZ 850I3, USA

Tel +l 6024064239

Fax +l 6024064606

Emailworjun@aol.com 
in the parasellar or petrous apex cavernous sinus regions represent an important etiology that can increase morbidity and mortality in adults $>50$ years of age.

\section{Patients and methods}

In a retrospective review of the medical records database over a 10-year period in a neuro-ophthalmology clinic in Reno, Nevada, USA, of 782 patients, consecutive patients with the selection criteria of $\geq 50$ years of age who had a diagnosis of isolated recurrent sixth nerve palsies were identified. Neurologically isolated palsy was defined as the absence of other symptoms and signs, with the exception of headache or periorbital pain within the first month of onset and during the follow-up period. Chronic was defined as $\geq 6$ months' duration. Recurrence of the sixth nerve palsy occurred on the same side during each of the episodes. The degree of eye deviation was measured by prism diopters during each office visit. Remission or recovery of the sixth nerve palsy was defined as a complete resolution of the angle of deviation. Medical history and laboratory studies for risk factors for microvascular disease, including hypertension, diabetes, hypercholesterolemia, and tobacco use were noted. Laboratory data for thyroid disorders, myasthenia gravis, and other infectious and autoimmune disorders were noted, including the following: 1) complete blood cell count with differential, electrolytes, liver function tests, blood urea nitrogen, creatinine, hemoglobin A1C, anti-nuclear antigen, sedimentation rate, c-reactive protein, platelets, rheumatoid factor, Venereal Disease Research Laboratory test, angiotensin-converting enzyme, Lyme titers, thyroid stimulating hormone, acetylcholine receptor antibodies, striated muscle antibodies; 2) cerebrospinal fluid for protein, glucose, cell count, Venereal Disease Research Laboratory test, routine culture, gram stain, acid-fast bacilli stain, cryptococcal antigen, fungal culture, multiple sclerosis panel, and Herpes simplex virus titers and Varicella zoster virus titers. Magnetic resonance imaging (MRI) of the brain and orbits with and without gadolinium and computerized tomographic (CT) angiogram of the brain were reviewed.

The short-term use of Fresnel prisms in spectacles, fogging of the lens with clear Scotch tape, or patching of one eye was used for the transient treatment of diplopia, depending on the patient's preference. Subsequent medical and/or surgical therapeutic interventions were reviewed for each patient included in this study.

Our results were compared with those of other similar studies from a current literature search on PubMed. Institutional review board approval was obtained for this chart review.

\section{Results}

In our consecutive series of seven patients who presented to a neuro-ophthalmology clinic over a 10 -year period, five males and two females ( $\geq 50$ years of age) were identified with a diagnosis of isolated recurrent sixth nerve palsies. They presented with recurrent horizontal diplopia without any associated headaches or ocular pain. The duration of these episodes of diplopia ranged from 2 weeks to 3 months. Intervals between these episodes ranged from 5 months to 2 years. Four of seven $(57 \%)$ patients had a tumor; one patient out of seven (14.29\%) had a recurrent painful ophthalmoplegic neuropathy (IHS 13.9), previously termed ophthalmoplegic migraine; one-seventh (14.29\%) had an intracavernous carotid artery aneurysm; and one out of seven patients $(14.29 \%)$ had an ischemic mononeuropathy related to hypertension and diabetes. Of those patients who had a tumor, three-quarters (75\%) had a meningioma and onequarter $(25 \%)$ had a metastatic melanoma (Table 1$)$.

\section{Discussion}

The differential diagnoses and workup of an isolated sixth nerve palsy usually depends on the age and the clinical circumstances of the patient. Patients younger than 50 years of age presenting with impaired abduction should undergo neuroimaging. If the results are normal, then 1)

Table I Causes of isolated recurrent sixth nerve palsy over a 10 -year period in a single clinic

\begin{tabular}{lll}
\hline Age, years & Sex & Causes of isolated recurrent sixth nerve palsy \\
\hline 52 & M & Intracavernous carotid artery aneurysm \\
57 & F & Recurrent painful ophthalmoplegic neuropathies (ophthalmoplegic migraine) \\
60 & M & Microvascular disease (hypertension and diabetes) \\
62 & M & Parasellar meningioma \\
71 & M & Petrous apex meningioma \\
72 & F & Metastatic melanoma in prepontine cistern cavernous sinus and sphenoid sinus \\
79 & M & Peripontine meningioma \\
\hline
\end{tabular}

Notes: In a retrospective review of the medical records database over a 10-year period in a neuro-ophthalmology clinic in Reno, Nevada, USA, of 782 patients, seven consecutive patients $\geq 50$ years of age were identified with a diagnosis of isolated recurrent sixth nerve palsies.

Abbreviations: $M$, male; $F$, female. 
neuromuscular junction disorders, such as myasthenia; 2) eye muscle restrictive disorders, such as thyroid eye disease; 3 ) meningeal infiltrative and metastatic processes, such as leukemia and brainstem glioma; and 4) demyelinative disorders, such as multiple sclerosis, need to be considered. ${ }^{1}$ In a study of 54 non-recurrent and 41 recurrent cases of pediatric idiopathic sixth nerve palsies, the risk factors for recurrence include: 1) female sex, 2) younger age, 3) left eye involvement, and 4) recent vaccination. Recurrence was less likely if it did not occur within 1 year of the initial presentation. ${ }^{3}$

Unlike palsies in younger persons, isolated sixth nerve palsies in adults $>50$ years of age are usually ischemic, and they typically resolve within 3 months. Neuroimaging is not required in these cases of isolated sixth nerve palsies in the clinical setting of diabetes, hypertension, and hyperlipidemia, but it is required if the sixth nerve palsy does not improve after 3 months. Other infectious and inflammatory causes, such as syphilis, collagen vascular disease, and sarcoidosis need to be ruled out with a lumbar puncture, blood testing, etc. ${ }^{1}$ Furthermore, neuroimaging is required especially when the isolated sixth nerve palsy is chronic and recurrent. In adults $>50$ years of age, the differential diagnosis of an isolated chronic recurrent sixth nerve palsy most commonly includes the following: 1) vasculopathy, ${ }^{4} 2$ ) dolichoectasia/aneurysm, ${ }^{5,6}$ 3) recurrent painful ophthalmoplegic neuropathy (previously termed ophthalmoplegic migraine), ${ }^{7}$ 4) sphenoiditis, ${ }^{8}$ 5) familial recurrent sixth nerve palsy, ${ }^{9}$ and 6) tumor. ${ }^{10,11}$ In the current retrospective case series over a 10 -year period, we present further evidence that non-microvascular causes, such as neoplasms and aneurysms, may be more common in the isolated chronic recurrent ipsilateral sixth nerve palsies in patients $>50$ years of age.

According to a 2002 study of 59 patients who had isolated sixth nerve palsies related to hypertension, diabetes, hyperlipidemia, and tobacco use, $86 \%$ completely resolved and $31 \%$ of cases recurred during a follow-up period of 6.1 years. ${ }^{4}$ Of those patients who had a tumor, three quarters (75\%) had a meningioma (Figure 1) and one-quarter (25\%) had a metastatic melanoma (Table1). One of 59 (16\%) patients had four recurrences, and the remaining 14 of 59 (23\%) patients had one recurrence. These recurrences involved the same eye in ten instances and the fellow eye in 14 instances. No risk factors were associated with recurrence or incomplete recovery. ${ }^{4}$ It is thought that the thickening and hyalinization of nutrient vessels leads to focal ischemic demyelination followed by remyelination and clinical recovery. ${ }^{12}$ In our study cohort, one-seventh (14.29\%) of patients had an ischemic mononeuropathy, with each episode lasting about 2 months and the duration between

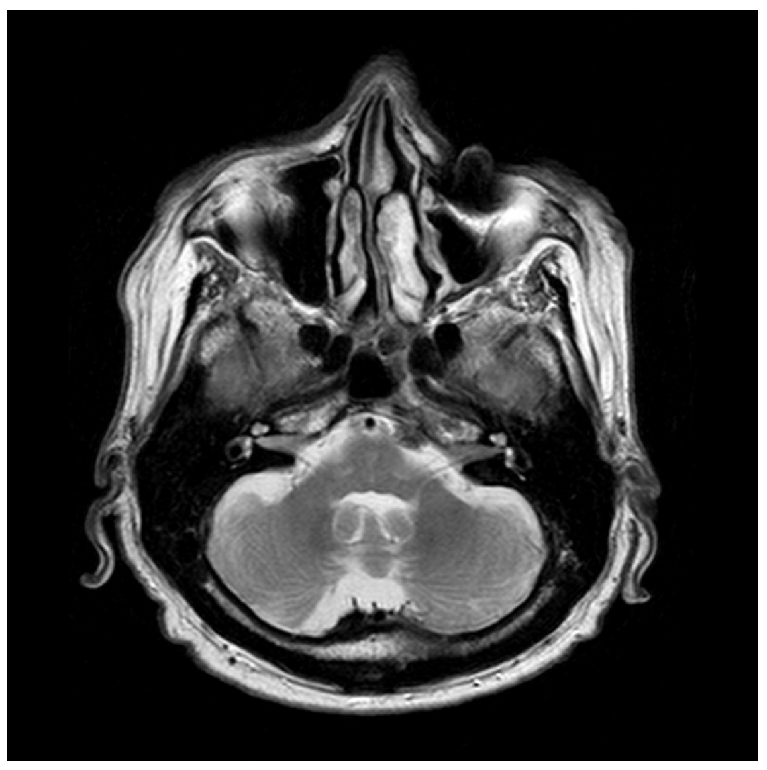

Figure I A left peripontine meningioma causing recurrent isolated sixth nerve palsies.

episodes lasting about 6 to 7 months. Our patient had the vasculopathic risk factors of hypertension and diabetes. Our 60-year old male patient with ischemic mononeuropathy had the vasculopathic risk factors of hypertension and diabetes. He continued to have recurrent ipsilateral sixth nerve palsies, because he was noncompliant with medical treatment of his hypertension and diabetes. Although there are no data from large clinical trials to support any definitive treatment for vasculopathic oculomotor palsies, improved control of the underlying vasculopathic risk factors may help prevent recurrences.

Ophthalmoplegic migraine, which is now termed recurrent painful ophthalmoplegic neuropathy (IHS 13.9) according to The International Classification of Headache Disorders, Third Edition (ICHD III) criteria, ${ }^{13}$ is another cause of chronic recurrent sixth nerve palsies in our study cohort of patients $\geq 50$ years of age. (The terminology of this disorder was recently revised because this pain syndrome is not considered migrainous, but rather a recurrent painful ocular cranial neuropathy with ipsilateral headache). Unlike childhood recurrent painful ophthalmoplegic neuropathies that usually present as a third nerve palsy in males, adult-onset cases often affect the sixth nerve, as was shown in the largest case series in adult recurrent painful ophthalmoplegic neuropathies, based on a consecutive series of 62 patients with severe migraine recruited between the years 1996-2005. These episodes usually happen just once and are rarely recurrent in adults. The pathophysiology of recurrent painful ophthalmoplegic neuropathies remains unclear. It has been hypothesized that vasospasm of the arterial supply to the sixth cranial nerve may cause ischemia followed by recovery of nerve 
function. ${ }^{11}$ It has also been thought that cranial neuropathies could represent repeated episodes of demyelination, seen as gadolinium enhancement of the nerve on MRI, with subsequent axonal damage. ${ }^{11}$ In our study cohort, one out of seven patients (14.29\%) had a recurrent painful ophthalmoplegic neuropathy, presenting as a relapsing-remitting ipsilateral sixth nerve palsy over an 8-month period. Unlike childhood recurrent painful ophthalmoplegic neuropathies involving the third cranial nerve, in which the nerve often enhances on MRI with gadolinium and/or develops focal enlargement, ${ }^{10}$ the sixth cranial nerve in our patient with opthhalmoplegic migraine did not show any pathological changes. Although treatment with corticosteroids has been beneficial in some patients, ${ }^{14,15}$ our 57-year-old female patient elected not to take prednisone because of the risk of adverse effects.

Although most tumors, such as gliomas, chordomas, chondrosarcomas, meningiomas, intracavernous aneurysms, and nonfunctioning pituitary macroadenomas with evidence of apoplexy, ${ }^{16,17}$ cause a chronic, compressive sixth nerve palsy, our study shows that tumors and aneurysms can also cause a chronic relapsing, remitting sixth nerve palsy. In our series of seven patients studied over a 10 -year period, four out of seven $(57 \%)$ patients had a tumor. Of those patients who had a tumor, three-quarters $(75 \%)$ had a meningioma and one-quarter $(25 \%)$ had a metastatic melanoma. One of seven $(14.29 \%)$ patients had an intracavernous carotid artery aneurysm. These patients were initially misdiagnosed as having such disorders as ocular myasthenia, recurrent painful ophthalmoplegic neuropathy, ischemic mononeuropathy, and thyroid eye disease. Because of the assumption of a benign disorder presenting as intermittent diplopia, these patients did not undergo an MRI of the brain until later in their workup. Our patients with a meningioma ultimately underwent stereotactic radiosurgery for partial debulking of the tumor, and the one patient with an intracavernous carotid artery aneurysm underwent endovascular treatment.

Petrous apex meningiomas and parasellar meningiomas have been shown in a previous study to cause a relapsingremitting sixth nerve palsy over a period of 6 to 7 years. ${ }^{11}$ This phenomenon of a relapsing-remitting course has also been shown to occur in other oculomotor nerves, specifically as a recurrent alternating oculomotor nerve palsy related to a parasagittal meningioma in a 57-year-old man. ${ }^{18,19}$ The exact pathophysiologic mechanism of the relapsing and remitting course of the sixth nerve palsy remains unclear. It has been hypothesized that the intermittent compression by a structural lesion could create a cycle of demyelination of the sixth nerve to cause weakness of the lateral rectus muscle, and then remyelination of the nerve to cause recovery of function. ${ }^{5}$ Another possible mechanism would involve direct compression of the arterial supply to the sixth nerve, which can lead to ischemia followed by aberrant regeneration of the sixth nerve to reinnervate the lateral rectus muscle for recovery of normal function between each episode of the sixth nerve palsy. ${ }^{6}$

\section{Conclusion}

Sixth nerve palsies presenting in a chronic recurrent course are relatively uncommon. Although spontaneous resolution of a sixth nerve palsy is generally considered adequate evidence of a vasculopathic etiology and a clinical feature that indicates MRI is not necessary, spontaneous recovery of non-recurrent sixth nerve palsies has been reported in patients with skull base tumors. ${ }^{20}$ The clinical presentation of a chronic isolated recurrent diplopia from a sixth nerve palsy should prompt the neurologist or ophthalmologist to order an MRI of the brain with and without gadolinium as part of the initial workup to rule out non-microvascular causes, such as neoplasms and aneurysms, that can increase morbidity and mortality in adults $>50$ years of age. We suggest that if there is no recovery of the sixth nerve palsy 3 months after onset, or if it is fluctuating chronically over 6 months, then a petrous apex cavernous sinus of a parasellar lesion should be considered.

\section{Disclosure}

The authors report no conflicts of interest in this work.

\section{References}

1. Richards BW, Jones FR Jr, Younge BR. Causes and prognosis in 4,278 cases of paralysis of the oculomotor, trochlear, and abducens cranial nerves. Am J Ophthalmol. 1992;113(5):489-496.

2. Tamhankar MA, Biousse V, Ying GS, et al. Isolated third, fourth, and sixth cranial nerve palsies from presumed microvascular versus other causes: a prospective study. Ophthalmology. 2013;120(11):2264-2269.

3. Yousuf SJ, Khan AO. Presenting features suggestive for later recurrence of idiopathic sixth nerve paresis in children. J AAPOS. 2007;11(5): $452-455$.

4. Sanders SK, Kawasaki A, Purvin VA. Long-term prognosis in patients with vasculopathic sixth nerve palsy. Am J Ophthalmol. 2002;134(1): 81-84.

5. Blumenthal EZ, Gomori JM, Dotan S. Recurrent abducens nerve palsy caused by dolichoectasia of the cavernous internal carotid artery. Am J Ophthalmol. 1997;124(2):255-257.

6. Nguyen DQ, Perera L, Kyle G. Recurrent isolated sixth nerve palsy secondary to an intracavernous carotid artery aneurysm. Eye (Lond). 2006;20(12):1416-1417.

7. Lal V, Sahota P, Singh P, Gupta A, Prabhakar S. Ophthalmoplegia with migraine in adults: is it ophthalmoplegic migraine? Headache. 2009; 49(6):838-850.

8. Gupta N, Michel MA, Poetker DM. Recurrent contralateral abducens nerve palsy in acute unilateral sphenoiditis. Am J Otolaryngol. 2010; 31(5):372-375.

9. Golnik KC, Miller NR. Familial recurrent cranial nerve palsy. J Neurol Neurosurg Psychiatry. 1992;55(10):976-977. 
10. Bek S, Genc G, Demirkaya S, Eroglu E, Odabasi Z. Ophthalmoplegic migraine. Neurologist. 2009;15(3):147-149.

11. Currie J, Lubin JH, Lessell S. Chronic isolated abducens paresis from tumors at the base of the brain. Arch Neurol. 1983;40(4):226-229.

12. Asbury AK, Aldredge H, Hershberg R, Fisher CM. Oculomotor palsy in diabetes mellitus: a clinico-pathological study. Brain. 1970; 93(3):555-566.

13. Headache Classification Committee of the International Headache Society (IHS). The International Classification of Headache Disorders, 3rd Edition (beta version). Cephalalgia. 2013;33(9):629-808.

14. Carlow TJ. Oculomotor ophthalmoplegic migraine: is it really migraine? J Neuroophthalmol. 2002;22(3):215-221.

15. Vasconcelos LP, Stancioli FG, Leal JC, da Silva A, Gómez RS, Teixeira AL. Ophthalmoplegic migraine: a case with recurrent palsy of the abducens nerve. Headache. 2008;48(6):961-964.
16. Galetta SL, Smith JL. Chronic isolated sixth nerve palsies. Arch Neurol. 1989;46(1):79-82.

17. Kim SH, Lee KC, Kim SH. Cranial nerve palsies accompanying pituitary tumour. J Clin Neurosci. 2007;14(12):1158-1162.

18. Gokce G, Ceylan OM, Altinsoy HI. Recurrent alternating oculomotor nerve palsy: an unusual presentation of parasagittal meningioma. Neuroopthalmol. 2013;37(2):82-85.

19. Gokce G, Ceylan OM, Mutlu FM, Altinsoy HI. Intracranial meningiomas and neurofibromatosis type 2. Acta Neurochir (Wien). 2014; 156(6): 1103.

20. Volpe NJ, Lessell S. Remitting sixth nerve palsy in skull base tumors. Arch Ophthalmol. 1993;111(10):1391-1395.
Clinical Ophthalmology

\section{Publish your work in this journal}

Clinical Ophthalmology is an international, peer-reviewed journal covering all subspecialties within ophthalmology. Key topics include: Optometry; Visual science; Pharmacology and drug therapy in eye diseases; Basic Sciences; Primary and Secondary eye care; Patien Safety and Quality of Care Improvements. This journal is indexed on

Submit your manuscript here: http://www.dovepress.com/clinical-ophthalmology-journal

\section{Dovepress}

PubMed Central and CAS, and is the official journal of The Society of Clinical Ophthalmology (SCO). The manuscript management system is completely online and includes a very quick and fair peer-review system, which is all easy to use. Visit http://www.dovepress.com/ testimonials.php to read real quotes from published authors. 